\title{
Designing sustainable city logistics distribution network using a probabilistic bi-objective mathematical model
}

\author{
Farshad Saeedi $^{\mathrm{a}}$, Ebrahim Teimoury ${ }^{\mathrm{b}^{*}}$ and Ahmad Makuic
}

${ }^{a}$ MSc Student, Department of Industrial Engineering, Iran University of Science and Technology

${ }^{b}$ Associate Prof., Department of Industrial Engineering, Iran University of Science and Technology

${ }^{c}$ Professor, Department of Industrial Engineering, Iran University of Science and Technology

\section{CH R O N I C L E}

Article history:

Received December18, 2017

Accepted March 152018

Available online

March 152018

Keywords:

City logistics

City distribution centers

Sustainability

Carbon emissions

Network design

Queuing theory

\begin{abstract}
A B S T R A C T
Today, urban areas have been considerably expanded, which has caused numerous problems due to the large population in metropolitan areas. City logistics models can be effective in solving complicated problems such as traffic congestion, air pollution, accidents, and high energy consumption rate. The present paper proposes a bi-objective mathematical model for designing a city logistics distribution network in order to minimize the economic and environmental costs as well as the response time. The proposed model would make decisions on the location and allocation problems in the city logistics distribution network. In fact, the objective of the problem is to select some fixed sites in order to construct the city distribution centers. The demand for commodities is considered probabilistic and the network is modeled based on the queuing theory. Furthermore, in the proposed model, the policy of putting tax on carbon and applying the low-carbon emission resources are used for establishment at the city distribution centers. Afterwards, in order to validate the proposed model, a numerical example is generated and, then, the results obtained from solving the model via epsilon constraint method are presented. Analysis of the results in the present study indicates that the proposed model was highly efficient in achieving its objectives. Finally, there are some suggestions for future studies that can be taken into account.
\end{abstract}

(C) 2018 by the authors; licensee Growing Science, Canada

\section{Introduction}

According to a UN research project, almost half of the seven billion population of the world in 2010 were living in urban areas and it is estimated to exceed $60 \%$ in 2030 and $70 \%$ in 2050 . Several metropolitan areas with the population of more than 10 million people have emerged and their massive population has created numerous problems. On the other hand, logistic advancements, such as timely and smart retailing, persuade sellers to keep their inventory at a low level in order to make savings on the storage costs. Due to these factors, there is an increase in the number of demands for commodities to be transferred to their destinations and at the same time, there is a decrease in the volume of these

* Corresponding author

E-mail address: teimoury@iust.ac.ir (E. Teimoury)

(C) 2018 by the authors; licensee Growing Science, Canada doi: $10.5267 /$ j.uscm.2018.3.001 
demands. Therefore, the traffic of freight vehicles in urban areas increases and hence, there is an increase in the percentage of pollutant emissions, which is a significant part of the freight transport. All of these problems, which have been caused by the displacement of urban commodities, highlight the necessity to think of how to plan cities so that such negative effects can be reduced without jeopardizing citizens' need for commodities. The concept of city logistics was presented to help solve such challenging issues (Taniguchi et al., 2001; Babaei \& Shahanaghi, 2017). City logistics solutions can be effective in solving such complicated problems, because city logistics considers several objectives along with the behaviors of several beneficiaries participating in city logistics activities, which consequently provides the foundations of sustainable and viable cities (Taniguchi et al., 2014). In this regard, using a variety of models, several policy actions have been implemented and evaluated in some of the cities around the world (Taniguchi \& Thompson, 2015; Jawla \& Singh, 2016).

Objectives of city logistics can be divided into three categories, including economic, environmental, and social (Taniguchi \& Thompson, 2015). From another perspective, city logistics seeks for multiple objectives regarding mobility, sustainability, viability, and flexibility. As for mobility, implementing urban commodities movement systems requires a smooth and integrated flow of commodities. Sustainability refers to the minimization of the negative environmental effects including air pollution, noise pollution, and vibrations caused by trucks. Apropos of viability, it should be noted that security and safety are the most important issues for any society, because citizens always seek for healthy and calm living conditions. Recently, more importance has been devoted on the flexibility in natural and human disasters. Distribution of relief aids, including water, food, and daily goods, among the people wandering in post-disaster shelters requires efficient and quick performance of humanitarian logistics.

In order to optimize city logistics distribution and minimize the economic and environmental costs of transporting commodities, a three-level network is introduced in the present study. Moreover, as the second objective function of the problem, it is attempted to minimize the response time in the network. Accordingly, the first level is composed of logistics centers around the city, the second level embraces the distribution centers within the city, and the third level includes the sales terminals as demand points. In fact, the objective of the problem is to select some fixed sites in order to construct city distribution centers. In addition, it would be necessary to make decisions on how much the capacity of distribution centers should be, how these distribution centers should be allocated to the logistics centers, and how sales terminals should be allocated to distribution centers. The demand for commodities is considered probabilistic and the network is modeled based on the queuing theory. Furthermore, in the proposed model, the policy of putting tax on carbon as well as applying the resources with low carbon emissions is used for establishment at the city distribution centers. In order to validate the model, a numerical example is generated and, then, the results obtained from solving the model via epsilon constraint method are presented. Analysis of the research results indicates that the proposed model is highly efficient in achieving its given objectives. Finally, an overall sum-up as well as some suggestions for future studies are provided.

\section{Literature review}

Review of the available literature on city logistics revealed several terms and interpretations used to investigate this concept (Wolpert \& Reuter, 2012); therefore, the city logistics should be considered in the broadest concept:

- Cargo transport in urban areas, specifically the freight flows associated with the supply of commodities to city centers (Barceló \& Pardo, 2005);

- Routing and transferring the commodities throughout all the transportation modes as well as subordinate activities such as storage and information exchange in order for managing the commodities at each end of the trips (Qiu \& Yang., 2005);

- Attempting to optimize the urban freight transportation systems while considering all the beneficiaries and displacements in urban areas (Crainic et al., 2009); 
- Providing any kind of services facilitating the optimal management of displacing the commodities in cities (Dablanc, 2007);

- Process of full optimization of logistics and transport activities by private companies by means of advanced information systems in urban areas with regard to the traffic environment, traffic congestion, traffic safety, and energy saving within the market economy's framework (Taniguchi et al., 2001).

City logistics was first introduced by Taniguchi in 2001. Since then, numerous studies have been conducted in this field and many researchers have expressed their points of view in this regard. However, so far, only a few models have been proposed with regard to mathematical modeling of city logistics, and even the proposed models have not been properly developed (Saeedi et al., 2017). In terms of reviewing, investigating, and identifying the related literature as well as modeling in the field of city logistics, several review studies have been provided by different researchers, including Anand et al. (2012), Taniguchi et al. (2014), Anand et al. (2015), Muñuzuri and Pablo (2012) and Wolpert and Reuter (2012).

Most of the mathematical models provided in recent papers have focused on vehicle routing in different case studies and aimed at the environmental and cost objectives. The problems related to public passenger transport, in contrast to the city logistics distribution problems, have been mostly neglected due to the sufficient maturity in the field of city logistics in recent years (Saeedi et al., 2017). Some of the papers in this regard are also focused on the city logistics network design in case of crisis and catastrophe and are related the issue of city logistics to the emergency logistics to some extent (He et al., 2013). Traffic systems are usually disrupted in case of a crisis; thus, it is necessary to detect the effective solutions for continuing distribution services for the cases, in which the urban traffic system's capacity is reduced. In fact, optimizing the location of logistic facilities in metropolitan areas is very important, not only in crisis situations, but also at any time, since its powerful effect on land use, traffic flow, and unwanted consequences such as traffic congestion and air pollution is of great importance (Duren \& Miller, 2012).

A review of the articles in this field shows that there is almost no study focusing on the demands of all four beneficiaries existing in the city logistics, including managers, senders, transporters, and customers. On the contrary, the problems have been mainly investigated from the viewpoint of urban authorities and managers. Moreover, sustainable and green objectives have been highly regarded by authors of the papers, who have often used linear mathematical programming method for modeling the problems (Saeedi et al., 2017). Among these works, Jianhua Yang et al. (2013) and Abdelhamid Moutaoukil et al. (2015) can be mentioned.

In order to make cities sustainable, numerous projects and innovations have been implemented to improve city logistics. The main objective of these projects is to reduce motor traffic and, as a result, reduce $\mathrm{CO} 2$ emissions and greenhouse gases in urban areas. This has been performed mainly through three ways: stabilizing flow of commodities, using low-emission vehicles, and establishing rules for controlling access to city centers. Stabilization of commodities, which is mainly based on the use of a distribution center, seems to be an appropriate solution for optimizing the final delivery within the city (Taniguchi \& Thompson, 2015).

Stabilization facilities for city logistics concepts are considered very useful by some authors; nevertheless, there is not yet a unique and coherent term that can describe such stabilization facilities. For example, Crainic refers to the urban development centers, while Dablanc considers them as urban freight terminals. Besides, the terms distribution village and city distribution centers have been also used (Taniguchi et al., 2014; Taniguchi \& Thompson, 2015; Wolpert \& Reuter, 2012).

City distribution centers are used to promote the cooperative transport systems, improve distribution of commodities (aggregation of similar commodities and use of fewer vehicles), reduce economic and environmental costs, and decrease traffic (Taniguchi \& Thompson, 2015). 
Meanwhile, mathematical modeling of city logistics using the queuing theory and with simultaneous consideration of economic and environmental objectives can be a new and attractive subject leading to the optimized operations of city transport in the city distribution network, especially due to the point that the environmental objectives are now regarded more than ever by city's managers and authorities as well as citizens because of their great impact on the health of citizens. Also, using the queuing approach, time of responding to demands in the system can be optimized as well, which in turn would lead to the increased customer satisfaction and, eventually, reduced logistics costs. Furthermore, it seems appropriate and essential to consider the response time in the city logistics distribution network as the objective function of minimization, especially in crisis conditions as well as in case of essential and degradable commodities.

\section{Problem presentation and mathematical modeling}

In the city, freight vehicles collect the commodities from logistics centers (LC) located around the city and, then, transfer them to the distribution centers (DC) for further processes (storage, packaging, barcoding, cutting, mixing, combining, loading, unloading, etc.). Finally, these commodities are widely distributed among the sales terminals (ST).

In this study, decisions were made on the location and allocation problem in the city logistics distribution network. In fact, the problem's objective was to select some fixed sites for constructing the city distribution centers. Due to the capital costs limitation, only a few distribution centers could be constructed, and among these activated centers, only a certain number would receive the government's supports for being equipped with low-carbon facilities (such as expensive equipment that consumes the liquid natural gas as fuel or more complex structures in the design of the distribution centers with optimal carbon rate). Moreover, similar to the common problems of facilities location, appropriate decisions must be made on how these terminals should be allocated to the distribution centers and how the distribution centers should be allocated to the logistics centers. Furthermore, with regard to the carbon tax policies applied by the government and urban managers, the costs incurred by the emission of greenhouse gases resulting from processing the commodities at the distribution center as well as transport operations by vehicles within the network should be taken into consideration as well. The ultimate objective is to minimize the total operational costs as well as to minimize the response time.

The network's structure was such that the commodities would be transported through three levels. Accordingly, the first level included the logistics centers around the city. The second level was composed of the distribution centers within the city, where the commodities were maintained and divided. From there, the commodities were transported to the third level, i.e. sales terminals, as demand points.

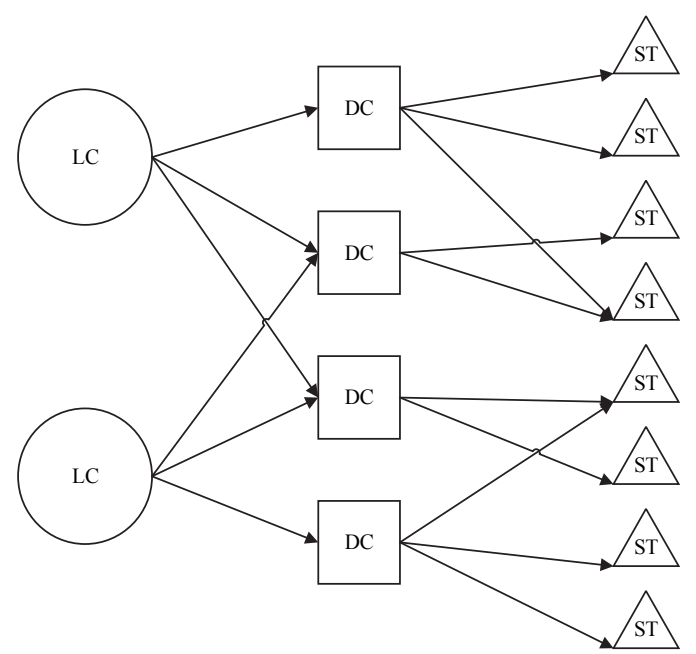

Fig. 1. City logistics distribution network (Saeedi et al., 2017) 
In this network, the network's nodes and commodities played the roles of server and customer, respectively. At the network's nodes, operations such as production, storage, packaging, barcoding, cutting, mixing, combining, loading, unloading, sorting, processing, and delivery were performed. These services were provided for commodities as customer. The conditions dominating the problem were associated with uncertainty; thus, under such conditions, the demand for commodities and service time was considered probabilistic.

\subsection{Assumptions}

- Each node of the network is considered as an M/M/1 queuing system.

- Service time at the network's nodes is probabilistic and is considered as having an exponential distribution function.

- Entry of demand into sales terminals is considered probabilistic with an exponential distribution function and the value of demand is considered as having a uniform distribution function.

- Carbon emission is linearly proportionate to the amount of delivered commodities and transport distance, although the carbon emission unit for logistics centers is different from that for distribution centers.

- At each distribution center, carbon emission is linearly proportionate to the number of commodities that are processed there (that are put in the process), but the cost of a unit emission inside each distribution center is different.

- Distribution centers' construction costs are linearly proportionate to the designed capacity, but the cost of a unit construction differs in different candidate sites.

- Each sales terminal can supply the demand for a certain commodity only from a single distribution center, but there is no limitation for supplying the sales terminals' demands from several distribution centers.

- Delivery costs are linearly dependent on the amount of goods and transport distance, although the unit of delivery costs differs for logistics or distribution centers.

\subsection{Symbols and parameters}

I Index for LCs

$\mathrm{J} \quad$ Index for DCs to be set up in candidate sites

$\mathrm{K} \quad$ Index for STs

$\mathrm{R} \quad$ Index for commodity

TC Total operational cost in network

RT System's response time

$D_{k}^{r} \quad$ Demands of commodity type $\mathrm{r}$ for ST $\mathrm{k}$

$\mathrm{d}_{\mathrm{ij}} \quad$ Distance from LC $\mathrm{i}$ to DC $\mathrm{j}$

$\mathrm{d}_{\mathrm{jk}} \quad$ Distance from DC $\mathrm{j}$ to $\mathrm{ST} \mathrm{k}$

$\mathrm{f}_{\mathrm{j}} \quad$ Unit construction cost for $\mathrm{DC} \mathrm{j}$

B Total fixed cost at DCs

$v_{j}^{r} \quad$ Cost unit of processing at distribution center $\boldsymbol{j}$ for r-type commodity

$t_{j}^{r} \quad$ Cost unit of transport of r-type commodity from distribution center $\boldsymbol{j}$ to each sales terminal

$s_{i}^{r} \quad$ Cost unit of transport of r-type commodity from logistics center $\boldsymbol{i}$ to each

distribution center

$\mathrm{pe}_{\mathrm{j}} \quad$ Carbon emission unit from all processing stages at distribution center $\boldsymbol{j}$

$t_{j} \quad$ Carbon emission unit of vehicles from distribution center $\boldsymbol{j}$ to each sales

te $\mathrm{j}_{\mathrm{j}}$ terminal 
Carbon emission unit of vehicles from logistic center $\boldsymbol{i}$ to each distribution center

$\mathrm{U}_{\mathrm{i}} \quad$ Commodity supply capacity of logistics center $\boldsymbol{i}$

W Number of DCs planned to construct

$\mathrm{V}$ Number of resources with low carbon emissions that should be allocated to the

distribution centers

a Carbon tax rate

b Carbon emission reduction percentage at each distribution center where the lowcarbon resources have been considered

$\lambda \quad$ Demand entry rate at network's nodes $\left(\lambda_{i}, \lambda_{j}\right.$ and $\left.\lambda_{k}\right)$

$\mu \quad$ Service-providing rate at network's nodes $\left(\mu_{i}, \mu_{j}\right.$ and $\left.\mu_{k}\right)$

$\delta \quad$ Parameter of negative exponential distribution

c Lower bound of a uniformly distributed random variable that indicates the quantity of commodity in a demand

d Upper bound of a uniformly distributed random variable that indicates the quantity of commodity in a demand

$t_{i j k}^{r} \quad$ Response time of the system for commodity type $\mathrm{r}$ from node $\mathrm{i}$ to node $\mathrm{k}$, going

through DC located at node $\mathrm{j}$

$W T_{\text {sys }}^{r} \quad$ Sojourn time of commodity type $\mathrm{r}$ in the system

$W T_{q}^{r} \quad$ Waiting time of commodity type $\mathrm{r}$ in the queue

$L R_{\text {sys }} \quad$ Average number of commodities in the system

$L R_{q} \quad$ Average number commodities in the queue

$T R_{i j}^{r} \quad$ Transportation time for commodity type $\mathrm{r}$ from node $\mathrm{i}$ to node $\mathrm{j}$

$T R_{j k}^{r} \quad$ Transportation time for commodity type $\mathrm{r}$ from node $\mathrm{j}$ to node $\mathrm{k}$

$v_{i j}^{r} \quad$ Transportation speed for commodity type $\mathrm{r}$ from node $\mathrm{i}$ to node $\mathrm{j}$

$v_{j k}^{r} \quad$ Transportation speed for commodity type $\mathrm{r}$ from node $\mathrm{j}$ to node $\mathrm{k}$

\subsection{Decision variables}

$x_{\mathrm{ij}}^{r} \quad$ Amount of r-type commodity that is carried from logistics center $\boldsymbol{i}$ to

distribution center $\boldsymbol{j}$

$\mathrm{Z}_{\mathrm{j}} \quad 1$ if $\mathrm{DC} \mathrm{j}$ is set up; 0 , otherwise

$\mathrm{C}_{\mathrm{j}} \quad$ Processing capacity designed at distribution center $\boldsymbol{j}$

$\mathrm{P}_{\mathrm{j}} \quad$ Equal to 1 if low-carbon resources are allocated to distribution center $\boldsymbol{j}$; otherwise,

$y_{i j}^{r} \quad 1$ if commodity type $\mathrm{r}$ is delivered from LC i to DC $\mathrm{j} ; 0$, otherwise

$y_{j k}^{r} \quad 1$ if commodity type $\mathrm{r}$ is delivered from DC $\mathrm{j}$ to ST $\mathrm{k} ; 0$, otherwise

\subsection{Mathematical model}

$$
\begin{array}{rl}
\operatorname{Min} T C=\left[\sum_{j} f_{j} C_{j} Z_{j}\right. & \left.+\sum_{j} \sum_{k} \sum_{r} v_{j}^{r} E\left(D_{k}^{r}\right) y_{j k}^{r}+\sum_{j} \sum_{k} \sum_{r} t_{j}^{r} E\left(D_{k}^{r}\right) d_{j k} y_{j k}^{r}+\sum_{i} \sum_{j} \sum_{r} s_{i}^{r} x_{i j}^{r} d_{i j}\right] \\
+a & a\left[\sum_{j}\left(1-b P_{j}\right) p e_{j} \sum_{k} \sum_{r} E\left(D_{k}^{r}\right) y_{j k}^{r}+\sum_{j} \sum_{k} \sum_{r} t e_{j} E\left(D_{k}^{r}\right) d_{j k} y_{j k}^{r}+\sum_{i} \sum_{j} \sum_{r} e_{i} x_{i j}^{r} d_{i j}\right]
\end{array}
$$

$\min R T=\sum_{i} \sum_{j} \sum_{k} \sum_{r} t_{i j k}^{r}$ 


$$
\begin{aligned}
& y_{i j}^{r} \leq Z_{j} \quad \forall i \in I, j \in J, r \in R \\
& y_{j k}^{r} \leq Z_{j} \quad \forall j \in J, k \in K, r \in R \\
& x_{\mathrm{ij}}^{r} \leq \mathrm{M} . y_{i j}^{r} \quad \forall i \in I, j \in J, r \in R \\
& P_{j} \leq Z_{j} \quad \forall j \in J \\
& C_{j} \leq M . Z_{j} \quad \forall j \in J \\
& C_{j} \geq \sum_{k} \sum_{r} E\left(D_{k}^{r}\right) y_{j k}^{r} \quad \forall j \in J \\
& \sum_{j} C_{j} \geq \sum_{k} \sum_{r} E\left(D_{k}^{r}\right) \\
& C_{j} \geq \sum_{i} \sum_{r} x_{\mathrm{ij}}^{r} \quad \forall j \in J \\
& \sum_{j} C_{j} \geq \sum_{i}^{r} \sum_{j} \sum_{r} x_{\mathrm{ij}}^{r} \\
& \sum_{j} \sum_{r} x_{\mathrm{ij}}^{r} \leq U_{i} \quad \forall i \in I \\
& \sum_{i}^{j} \sum_{j}^{r} \sum_{r} x_{\mathrm{ij}}^{r} \leq \sum_{i} U_{i} \\
& \sum_{j} E\left(D_{k}^{r}\right) y_{j k}^{r} \geq E\left(D_{k}^{r}\right) \quad \forall k \in K, r \in R \\
& \sum_{i} x_{\mathrm{ij}}^{r} \geq \sum_{k} E\left(D_{k}^{r}\right) y_{j k}^{r} \quad \forall j \in J, r \in R \\
& \begin{array}{ll}
\sum_{i} \sum_{r} x_{\mathrm{ij}}^{r} \geq \sum_{k} \sum_{r} E\left(D_{k}^{r}\right) y_{j k}^{r} & \forall j \in J \\
\sum_{i} \sum_{j}^{r} x_{\mathrm{ij}}^{r} \geq \sum_{j}^{r} \sum_{k} E\left(D_{k}^{r}\right) y_{j k}^{r} & \forall r \in R
\end{array} \\
& \sum_{i} \sum_{j} \sum_{r} x_{\mathrm{ij}}^{r} \geq \sum_{k} \sum_{r} E\left(D_{k}^{r}\right) \\
& \sum_{j \in J} f_{j} z_{j} \leq B \quad \forall i, j, r \\
& \sum_{j}^{j \in j} Z_{j} \leq W \\
& \sum P_{j} \leq V \\
& \sum_{j} \sum_{r} y_{i j}^{r} \geq 1 \quad \forall i \in I \\
& \sum_{k} \sum_{r}^{r} y_{j k}^{r} \geq z_{j} \quad \forall j \in J \\
& \sum_{i} y_{i j}^{r}=z_{j} \quad \forall j \in J, r \in R \\
& \sum_{j} y_{j k}^{r}=1 \quad \forall k \in K, r \in R \\
& t_{i j k}^{r}=W T_{i}^{r}+W T_{j}^{r}+W T_{k}^{r}+T R_{i j}^{r}+T R_{j k}^{r} \\
& Z_{j}, P_{j} y_{i j}^{r}, y_{j k}^{r}=0,1 \quad \forall i \in I, j \in J, k \in K, r \in R
\end{aligned}
$$




$$
\begin{array}{ll}
x_{\mathrm{ij}}^{r} \geq 0 \cap x_{\mathrm{ij}}^{r} \in Z & \forall i \in I, j \in J, r \in R \\
C_{j} \geq 0 \cap C_{j} \in Z & \forall j \in J
\end{array}
$$

The first objective function minimizes the total operational cost. The total operational cost is comprised of two parts, the first of which is the total operation cost regardless of the carbon tax cost, and the second is the carbon tax cost imposed on carbon due to implementation of the carbon tax policy. The first part includes four items: fixed cost of constructing the distribution center, total variable cost of processing at the distribution center, total cost of delivery from distribution centers to sales terminals, and total cost of transportation from logistics centers to distribution centers. On the other hand, the second part consists of three items: the carbon cost resulting from the processing stages at distribution center, cost of delivery from distribution center to sales terminal, and cost of transport from logistics center to distribution center. Moreover, the second objective function minimizes the total response time in the network as well.

Constraints (3) and (4) state that a distribution center cannot join the distribution activities as long as it is not constructed. Constraint (5) states that some amount of a certain commodity will be delivered from a certain logistics center to a certain distribution center only when the relationship between that logistics and distribution center has been established. Constraint (6) states that only the activated distribution centers will be equipped with low-carbon resources and equipment. Constraint (7) states that only the activated distribution centers will have capacity. Constraint (8) expresses that the capacity of each distribution center should be larger than or equal to its total output flow. Constraint (9) states that the sum of capacities of all distribution centers should be larger than or equal to the sum of demands of the sales terminals. Constraint (10) states that the capacity of each distribution center should be larger than or equal to its total input flow. Constraint (11) states that the sum of capacities of all distribution centers should be larger than or equal to the total flow that is transferred from all logistics centers to all distribution centers, which means that the distribution centers should be large enough for storing all the commodities carried from logistics centers. Constraints (12) and (13) refer to the logistics center's ability to supply commodities. Constraint (12) indicates that the total amount of the commodity that is transferred from each logistics center to the distribution centers should be less than the capacity of that logistics center. Constraint (13) also shows that the total amount of the commodity that is transferred from logistics centers to distribution centers should be less than total capacity of the logistics centers. Constraint (14) states that the sum of flows of the r-type commodity entering from all distribution centers into each sales terminal should meet the demand for the r-type commodity of that sales terminal. Constraint (15) shows that for each commodity, the input flow to each distribution center should be larger than or equal to its output flow. Constraint (16) states that the total input flow to a distribution center should be larger than or equal to its total output flow. Constraint (17) states that for each commodity, sum of the output flows coming out of all logistics centers should be larger than or equal to the sum of demands of all distribution centers. Constraint (18) shows that the total output flow coming out of the logistics centers should meet the total demand of the sales terminals. Constraint (19) states that the sum of fixed costs of the activated distribution centers should not be larger than the value of the available budget. Constraint (20) shows that W distribution centers should be constructed. Constraint (21) states that the resources with low carbon emission should be allocated only to V activated distribution centers. Constraint (22) ensures that all logistics centers will join the distribution activities. Constraint (23) states that none of the activated distribution centers should be without relationship. In fact, the purpose of considering Constraints (22) and (23) is to utilize the potential of all logistical centers and activated distribution centers for supplying the commodities. In cases that the capacity of the intended centers is at such a level that may seem very difficult even to supply demands of the sales terminals in unit of time, there will be no need for considering these two constraints, and the model itself will attempt to utilize the capacity of all these centers in order to supply the given demand. Constraint (24) shows that each distribution center can obtain its demand for r-type commodity 
from a single logistics center at most. Similarly, Constraint (25) shows that each sales terminal can obtain its demand for r-type commodity from at most a single distribution center. Constraint (26) shows that the system's response time for r-type commodity, which is carried from the logistics center $\boldsymbol{i}$ to the sales terminal $\boldsymbol{k}$ through the distribution center $\boldsymbol{j}$, is equal to that commodity's duration of presence at the first to third levels of the network plus the transportation time of that commodity between the network's levels. It should be noted that the total time of presence in the system $\left(W T_{\text {sys }}\right)$ is equal to the sum of the times of presence at the first to third levels of the network. Constraint (27) states that variables $Z_{j}, P_{j}, y_{i j}^{r}$, and $y_{j k}^{r}$ can take the values of 0 and 1 . Constraint (28) and (29) also express that variables $x_{\mathrm{ij}}^{r}$ and $C_{j}$ have non-negative and integer values.

\subsection{Queuing model}

The studied queuing network was a series-parallel network consisted of three levels. At each serviceproviding node in the network, the queuing system was assumed as $\mathrm{M} / \mathrm{M} / 1$ and service-providing was performed with an exponential distribution with $\boldsymbol{\mu}$ parameter. Besides, the system was based on the FIFO (first-in/first-out) approach. It was assumed that the demand for commodities at demand point $\boldsymbol{k}$ followed an exponential distribution with parameter $\lambda_{k}$. Since each distribution center provided services for a group of the demand points, the demand of each of these distribution centers $\left(\lambda_{j}\right)$ would be equal to the total demand of its relevant downstream service-receivers. Therefore, it followed the following equation:

$$
\lambda_{j}=\sum_{k} \lambda_{k} y_{j k} \quad \forall j \in J
$$

Moreover, commodity demand for logistics centers followed the exponential distribution, the parameter of which can be obtained through the following equation:

$$
\lambda_{i}=\sum_{j} \lambda_{j} y_{i j}=\sum_{j} \sum_{k} \lambda_{k} y_{i j} y_{j k} \quad \forall i \in I
$$

Therefore, the schematic figure of the network would be as follows:

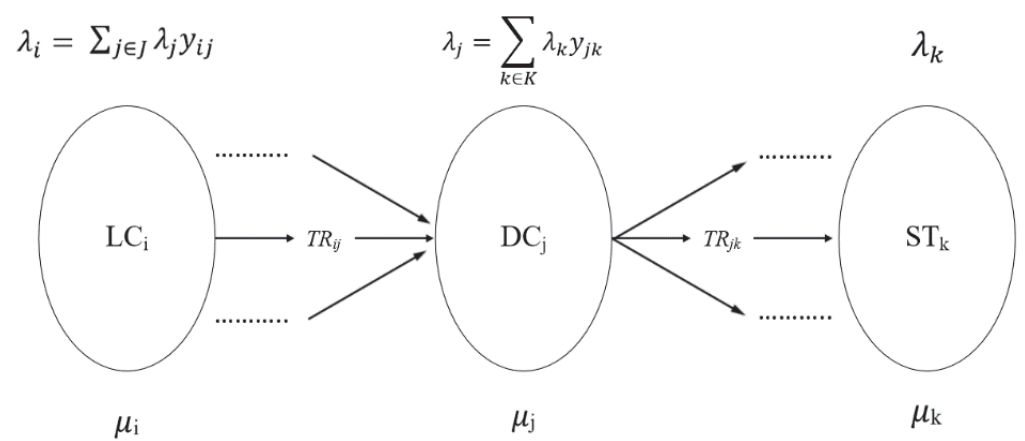

Fig. 2. Queuing system of city logistics distribution network

In this model, the demand for a commodity was expressed by two indices of demand occurrence and demand size at each time of occurrence. It was assumed that occurrence of the demand for each commodity was random variable $\mathrm{U}$ with exponential distribution and density function $f_{u}(u)$, and the demand size at each time of occurrence was random variable $\mathrm{V}$ with uniform distribution and density function $f_{v}(v)$.

Since these two random variables were independent from each other, the following equations held true:

$$
f_{U}(u)=\left\{\begin{array}{rr}
\delta e^{-\delta u}, & u \geq 0 \\
0, & u<0
\end{array}\right.
$$




$$
\begin{aligned}
& f_{V}(v)=\left\{\begin{aligned}
\frac{1}{d-c}, & c<v<d \\
0, & \text { otherwise }
\end{aligned}\right. \\
& E(D)=E(U V)=E(U) E(V)=\frac{c+d}{2 \delta}
\end{aligned}
$$

Therefore, in the multi-commodity model of the present study, we had:

$$
E\left(D_{k}^{r}\right)=\frac{c_{k}^{r}+d_{k}^{r}}{2 \delta_{k}^{r}}
$$

The r-type commodity demand of the sales terminals (demand points) followed the exponential distribution with parameter $\lambda_{k}^{r}$. Also, $\rho$ was the productivity rate and the following equations held true:

$$
\begin{aligned}
& \lambda_{k}^{r}=\frac{1}{E\left(D_{k}^{r}\right)}=\frac{2 \delta_{k}^{r}}{c_{k}^{r}+d_{k}^{r}} \\
& \rho=\frac{\lambda_{k}^{r}}{\mu_{k}}=\frac{1}{\mu_{k} E\left(D_{k}^{r}\right)}=\frac{2 \delta_{k}^{r}}{\mu_{k}\left(c_{k}^{r}+d_{k}^{r}\right)}
\end{aligned}
$$

According to the queuing theory, indices of the M/M/1 queuing model were as follows (Saeedi et al., 2017):

$$
\begin{aligned}
& f_{w t}(t)=(\mu-\lambda) e^{-(\mu-\lambda) t} \\
& F_{W T}(t)=P(W T \leq t)=\int_{0}^{t}(\mu-\lambda) e^{-(\mu-\lambda) t} d t=1-e^{-(\mu-\lambda) t} \\
& W T=E(W T)=\int_{0}^{\infty} f_{w t}(t) t d t=\int_{0}^{\infty}(\mu-\lambda) e^{-(\mu-\lambda) t} t d t=\frac{1}{\mu-\lambda} \\
& W T_{q}=W T-\frac{1}{\mu}=\frac{\lambda}{\mu(\mu-\lambda)} \\
& L R=\lambda W T=\frac{\lambda}{\mu-\lambda} \\
& L R_{q}=\lambda W T_{q}=\frac{\lambda^{2}}{\mu(\mu-\lambda)}
\end{aligned}
$$

According to the above-mentioned discussions and equations, with regard to our discussion on the queuing model of the given problem in the present study, Eq. (44) shows the average duration of stay in the system in three stages of the network. Eq. (45), Eq. (46), and Eq. (47) show the average duration of waiting in the queue, average number of commodities existing in the system, and average number of commodities waiting in the queue, respectively.

$$
\begin{aligned}
W T_{s y s}=\sum_{r} \sum_{i} W T_{I}^{R}+\sum_{r} \sum_{j} W T_{J}^{R}+\sum_{r} \sum_{k} W T_{K}^{R}=\sum_{r} \sum_{i} \frac{1}{\mu_{i}-\lambda_{i}}+\sum_{r} \sum_{j} \frac{1}{\mu_{j}-\lambda_{j}}+\sum_{r} \sum_{k} \frac{1}{\mu_{k}-\lambda_{k}} \\
=\sum_{r} \sum_{i} \frac{1}{\mu_{i}-\sum_{j} \sum_{k} \frac{2 \delta_{k}^{r}}{c_{k}^{r}+d_{k}^{r}} y_{i j}^{r} y_{j k}^{r}}+\sum_{r} \sum_{j} \frac{1}{\mu_{j}-\sum_{k} \frac{2 \delta_{k}^{r}}{c_{k}^{r}+d_{k}^{r}} y_{j k}^{r}}+\sum_{r} \sum_{k} \frac{1}{\mu_{k}-\frac{2 \delta_{k}^{r}}{c_{k}^{r}+d_{k}^{r}}} \\
W T_{q}=\sum_{r} \sum_{i} \frac{\lambda_{i}}{\mu_{i}\left(\mu_{i}-\lambda_{i}\right)}+\sum_{r} \sum_{j} \frac{\frac{\lambda_{j}}{\mu_{j}\left(\mu_{j}-\lambda_{j}\right)}}{\mu_{j}} \sum_{r} \sum_{k} \frac{\lambda_{k}}{\mu_{k}\left(\mu_{k}-\lambda_{k}\right)} \\
=\sum_{r} \sum_{i} \frac{\sum_{j} \sum_{k} \frac{2 \delta_{k}^{r}}{c_{k}^{r}+d_{k}^{r}} y_{i j} y_{j k}^{r}}{\mu_{i}\left(\mu_{i}-\sum_{j} \sum_{k} \frac{2 \delta_{k}^{r}}{c_{k}^{r}+d_{k}^{r}} y_{i j}^{r} y_{j k}^{r}\right)}+\sum_{r} \sum_{j} \frac{\sum_{k} \frac{2 \delta_{k}^{r}}{c_{k}^{r}+d_{k}^{r}} y_{j k}^{r}\left(\mu_{j}-\sum_{k} \frac{2 \delta_{k}^{r}}{c_{k}^{r}+d_{k}^{r}} y_{j k}^{r}\right)}{\frac{2 \delta_{k}^{r}}{c_{k}^{r}+d_{k}^{r}}} \\
+\sum_{r} \sum_{k} \frac{\left.2 \delta_{k}^{r}\right)}{\mu_{k}\left(\mu_{k}-\frac{2 d_{k}^{r}}{c_{k}^{r}+d_{k}^{r}}\right)}
\end{aligned}
$$




$$
\begin{aligned}
& L R_{s y s}=\sum_{r} \sum_{i} \frac{\lambda_{i}}{\left(\mu_{i}-\lambda_{i}\right)}+\sum_{r} \sum_{j} \frac{\lambda_{j}}{\left(\mu_{j}-\lambda_{j}\right)}+\sum_{r} \sum_{k} \frac{\lambda_{k}}{\left(\mu_{k}-\lambda_{k}\right)} \\
& =\sum_{r} \sum_{i} \frac{\sum_{j} \sum_{k} \frac{2 \delta_{k}^{r}}{c_{k}^{r}+d_{k}^{r}} y_{i j} y_{j k}^{r}}{\left(\mu_{i}-\sum_{j} \sum_{k} \frac{2 \delta_{k}^{r}}{c_{k}^{r}+d_{k}^{r}} y_{i j}^{r} y_{j k}^{r}\right)}+\sum_{r} \sum_{j} \frac{\sum_{k} \frac{2 \delta_{k}^{r}}{c_{k}^{r}+d_{k}^{r}} y_{j k}^{r}}{\left(\mu_{j}-\sum_{k} \frac{2 \delta_{k}^{r}}{c_{k}^{r}+d_{k}^{r}} y_{j k}^{r}\right)}+\sum_{r} \sum_{k} \frac{\frac{2 \delta_{k}^{r}}{c_{k}^{r}+d_{k}^{r}}}{\left(\mu_{k}-\frac{2 \delta_{k}^{r}}{c_{k}^{r}+d_{k}^{r}}\right)} \\
& L R_{q}=\sum_{r} \sum_{i} \frac{\lambda_{i}{ }^{2}}{\mu_{i}\left(\mu_{i}-\lambda_{i}\right)}+\sum_{r} \sum_{j} \frac{\lambda_{j}{ }^{2}}{\mu_{j}\left(\mu_{j}-\lambda_{j}\right)}+\sum_{r} \sum_{k} \frac{\lambda_{k}{ }^{2}}{\mu_{k}\left(\mu_{k}-\lambda_{k}\right)} \\
& =\sum_{r} \sum_{i} \frac{\left(\sum_{j} \sum_{k} \frac{2 \delta_{k}^{r}}{c_{k}^{r}+d_{k}^{r}} y_{i j} y_{j k}^{r}\right)^{2}}{\mu_{i}\left(\mu_{i}-\sum_{j} \sum_{k} \frac{2 \delta_{k}^{r}}{c_{k}^{r}+d_{k}^{r}} y_{i j}^{r} y_{j k}^{r}\right)}+\sum_{r} \sum_{j} \frac{\left(\sum_{k} \frac{2 \delta_{k}^{r}}{c_{k}^{r}+d_{k}^{r}} y_{j k}^{r}\right)^{2}}{\mu_{j}\left(\mu_{j}-\sum_{k} \frac{2 \delta_{k}^{r}}{c_{k}^{r}+d_{k}^{r}} y_{j k}^{r}\right)} \\
& +\sum_{r} \sum_{k} \frac{\left(\frac{2 \delta_{k}^{r}}{c_{k}^{r}+d_{k}^{r}}\right)^{2}}{\mu_{k}\left(\mu_{k}-\frac{2 \delta_{k}^{r}}{c_{k}^{r}+d_{k}^{r}}\right)}
\end{aligned}
$$

Based on the above points, the second objective function of the problem (Eq. (2)), which was equal to the total response time, was generally built up of aggregation of five parts:

$$
\min R T=W T_{s y s}+\sum_{r} \sum_{i} \sum_{j} T R_{i j}^{r} y_{i j}^{r}+\sum_{r} \sum_{j} \sum_{k} T R_{j k}^{r} y_{j k}^{r}
$$

By substituting, the following function was obtained:

$$
\begin{aligned}
\min R T=\sum_{r} \sum_{i} & \frac{1}{\mu_{i}-\sum_{j} \sum_{k} \frac{2 \delta_{k}^{r}}{c_{k}^{r}+d_{k}^{r}} y_{i j}^{r} y_{j k}^{r}}+\sum_{r} \sum_{j} \frac{1}{\mu_{j}-\sum_{k} \frac{2 \delta_{k}^{r}}{c_{k}^{r}+d_{k}^{r}} y_{j k}^{r}}+\sum_{r} \sum_{k} \frac{1}{\mu_{k}-\frac{2 \delta_{k}^{r}}{c_{k}^{r}+d_{k}^{r}}} \\
& +\sum_{r} \sum_{i} \sum_{j} T R_{i j}^{r} y_{i j}^{r}+\sum_{r} \sum_{j} \sum_{k} T R_{j k}^{r} y_{j k}^{r}
\end{aligned}
$$

\subsection{Linearization of the first objective function}

In the above model, item (1) in both the first and second parts of the first objective function included the multiplication of two decision variables. To simplify the solution, it can be linearized using the following method.

For the first item in the first part, the following logical method can be used:

$$
A C_{j}=\left\{\begin{array}{cc}
C_{j} & \text { if } Z_{j}=1 \\
0 & \text { if } Z_{j}=0
\end{array}\right.
$$

By this definition, the previous multiplication of variables $C_{j}$ and $Z_{j}$ were converted into a single variable $A C_{j}$. The $A C_{j}$ equations based on $Z_{j}$ were represented in constraints of the model. However, regarding Constraint (7), variable $Z_{j}$ can be entirely removed from the objective function without defining a variable such as $A C_{j}$.

For item (1) in the second part, the optimal solution can be obtained under the following conditions:

$$
C_{j}=\sum_{j} \sum_{k} \sum_{r} E\left(D_{k}^{r}\right) y_{j k}^{r}
$$

Therefore, here, $C_{j}$ is replaced for $\sum_{j} \sum_{k} \sum_{r} E\left(D_{k}^{r}\right) y_{j k}^{r}$. A non-negative interval variable $\boldsymbol{M C}$ was created, which can be specified as following:

$$
M C_{j}= \begin{cases}(1-b) p e_{j} \cdot C_{j} & \text { if } P_{j}=1 \\ p e_{j} \cdot C_{j} & \text { if } P_{j}=0\end{cases}
$$

Similarly, the $P_{j}$-based logical equations $M C_{j}$ are shown in the model's set of constraints.

Now, the first objective function of the problem can be specified as follows: 


$$
\begin{aligned}
\operatorname{Min} T C=\left[\sum_{j} f_{j} A C_{j}\right. & \left.+\sum_{j} \sum_{k} \sum_{r} v_{j}^{r} E\left(D_{k}^{r}\right) y_{j k}^{r}+\sum_{j} \sum_{k} \sum_{r} t_{j}^{r} E\left(D_{k}^{r}\right) d_{j k} y_{j k}^{r}+\sum_{i} \sum_{j} \sum_{r} s_{i}^{r} x_{i j}^{r} d_{i j}\right] \\
+ & a\left[\sum_{j} M C_{j}+\sum_{j} \sum_{k} \sum_{r} t e_{j} E\left(D_{k}^{r}\right) d_{j k} y_{j k}^{r}+\sum_{i} \sum_{j} \sum_{r} e_{i} x_{i j}^{r} d_{i j}\right]
\end{aligned}
$$

\section{Numerical example}

Cost of the processing variable in the distribution centers uniformly ranged between 10 and 20 monetary units. The maximum available budget for constructing the distribution centers was 30000 monetary units. Besides, according to the program, a maximum number of 5 distribution centers would be constructed, only two of which would be equipped with low-carbon equipment due to the capital constraints. The carbon emission reduction percentage at any distribution center, where the low-carbon resources were considered, was equal to $50 \%$. Also, the carbon tax rate was assumed equal to $30 \%$.

The service-providing rate at the first to third levels of the network was assumed equal to 12 , 8 , and 4 , respectively. The occurrence of demand at sales terminals had an exponential distribution with parameter $\delta$, the values of which were considered uniformly between 3 and 5 . The upper and lower limits of a uniform distribution function, which determined the demand value for each commodity, were assumed equal to 40 and 80 , respectively. The average speed of the vehicles at the first and second levels of the network was equal to 30 and $20 \mathrm{~km} / \mathrm{h}$, respectively. Naturally, the transportation time between the network levels was equal to the distances of the network points divided by the mean speed. Other parameters are initialized in Table 3:

\section{Table 1}

Values of other parameters of the numerical example

\begin{tabular}{cl}
\hline$v_{j}^{r}$ & Uniformly ranging between 10 and 20 monetary units per unit of commodity \\
$t_{j}^{r}$ & Uniformly ranging between 4 and 5 monetary units per unit of commodity and unit of distance \\
$s_{i}^{r}$ & Uniformly ranging between 2 and 4 monetary units per unit of commodity and unit of distance \\
$p e_{j}$ & Uniformly ranging between 100 and 600 units of carbon emission per unit of commodity \\
$t e_{j}$ & Uniformly ranging between 0.5 and 3 units of carbon emission per unit of commodity and unit of distance \\
$e_{i}$ & Uniformly ranging between 1 and 2 units of carbon emission per unit of commodity and unit of distance \\
$U_{i}$ & Uniformly ranging between 1000 and 2000 units of commodity \\
\hline
\end{tabular}

Considering the above values, now, we are going to describe the results obtained from solving the model via epsilon constraint method and by BARON solver in GAMS software. Epsilon constraint method is based on converting a multi-objective optimization problem into a single-objective optimization problem. This method is one of the most well-known approaches for dealing with the multi-objective optimization problems, which solves such problems by transferring all the objective functions, except one, to the constraints at each stage. In fact, in this method, one of the objectives of the given problem is optimized as the main objective relative to the other objectives as constraints, which is called epsilon constraint (Ehrgott, 2005; Bérubé, 2009). This method was first developed by Haimes et al. (1971) and, then, its details were described in Chankong and Haimes (1983) study. In the proposed problem in the present study, the first objective, i.e. the total operational cost, was investigated as the main objective and the second objective, i.e. the response time, as the secondary objective. Therefore, regarding the epsilon constraint method, formulation of the objectives was as follows:

$$
\begin{aligned}
& \min T C \\
& R T \leq \varepsilon
\end{aligned}
$$

In order to determine the Pareto points, first, each objective function was solved separately. The obtained results are reported in Table 2. 
Table 2

Results of solving the model using each objective function separately

\begin{tabular}{lllllll}
\hline Objectives & TC & RT & $\mathrm{Z}_{\mathrm{j}}$ & $\mathrm{P}_{\mathrm{j}}$ & $\mathrm{WT}_{\mathrm{q}}$ & $\mathrm{LR}_{\mathrm{q}}$ \\
\hline Min TC & 3706702.610 & 37.519 & $2,3,8$ & 2,3 & 8.235 & 5.061 \\
Min RT & 10583940.000 & 31.703 & $1,2,6$ & 1,2 & 8.589 & 2.094 \\
\hline
\end{tabular}

The ideal value of the first objective function was 3706702.610 and the worst value of the second objective function was 37.519; the problem did not have multiple optimal solutions. Therefore, there was no solution that can overcome the above optimal solution. Subsequently, based on epsilon constraint method and having $\Delta=0.5$, the optimal points of the were are generated; then, the best found solutions, i.e. the non-dominated Pareto solutions, were provided for the objective functions. In the consecutive repetitions of epsilon constraint method, 10 solutions were obtained for the given problem, the features of which are shown in Table 3. The values of the objective functions presented in the first and last rows of this table represent the ideal and nadir values for the two objective functions.

\section{Table 3}

Results of solving the model for different epsilon values

\begin{tabular}{llll}
\hline Number & $\varepsilon$ & Objective 1 (TC) & Objective 2 (RT) \\
\hline 1 & - & 3706702.610 & 37.519 \\
2 & 37.019 & 3734731.98 & 35.817 \\
3 & 36.519 & 3724240.95 & 34.542 \\
4 & 36.019 & 3732468.74 & 35.540 \\
5 & 35.519 & 3727184.93 & 35.817 \\
6 & 35.019 & 3763387.52 & 34.542 \\
7 & 34.519 & 3796109.93 & 35.54 \\
8 & 34.019 & 3989644.42 & 35.031 \\
9 & 33.519 & 3871823.28 & 34.791 \\
10 & - & 10583940.00 & 31.703 \\
\hline
\end{tabular}

It should be noted that some of these points were dominated by some others and, thus, removed from among the effective and Pareto solutions. Table 3 shows the dominated and non-dominated points in the absence of the ideal and nadir values of the objective functions. The blue points are dominated by green ones.

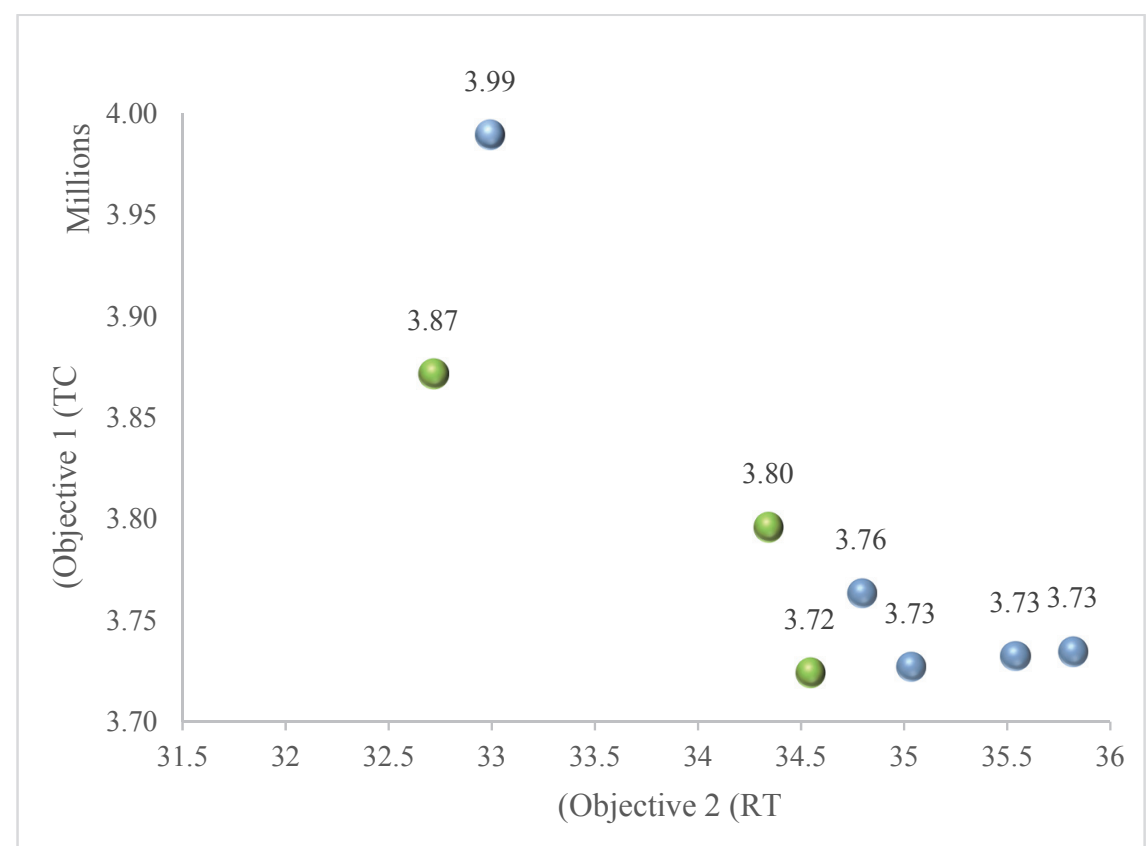

Fig. 3. Dominated and non-dominated points 
The following figure demonstrates all the Pareto and effective points after eliminating the dominated points. Accordingly, the number of Pareto solutions obtained for this problem with $\Delta=0.5$ was equal to five points.

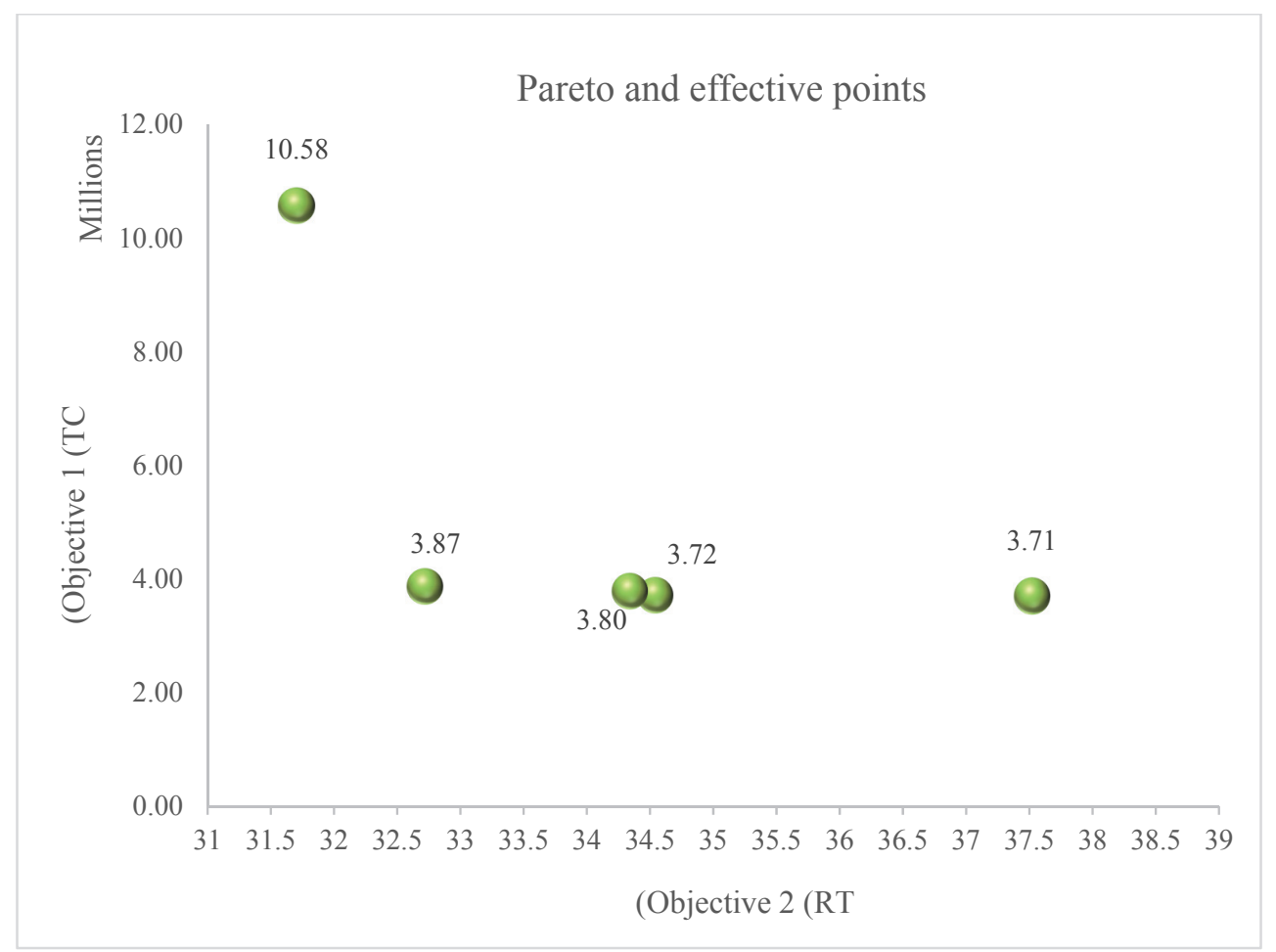

Fig. 4. Pareto points of the problem

One of the effective points for implementation is selected based on the priorities of the decision-makers and beneficiaries. The important notable point about the set of effective points obtained from epsilon constraint method is the completeness and accuracy of this set. In other words, in case of using other multi-objective problem solving methods for the mathematical model, the final solution of these methods will be one of the effective solutions obtained via epsilon constraint method.

\section{Sensitivity analysis}

This section deals with a sensitivity analysis on the given numerical example in order to investigate validity and behavior of the mathematical model and find the effect of changing the model's parameters on the given problem. For this purpose, effects of the $20 \%$ increase and reduction in the parameters, including service-providing rate at the network's nodes $(\mu)$, demand occurrence rate $(\delta)$, and carbon tax rate (a), on the objective functions and queuing network criteria were taken into consideration. Although other parameters of the model might also affect the objective functions, only the basic parameters given for investigating the model's validity and behavior were considered. To perform the sensitivity analysis, the first objective function was considered as the main objective function.

Fig. (5) shows the effect of different values of service-providing rate at the network's nodes on values of the objective functions and queuing network criteria. As could be expected, by changing the serviceproviding rate at nodes of the network, no change occurred in the value of the first objective function, i.e. the total operational costs. That is because, basically, this objective function is not dependent on the service-providing rate, which is clearly evident in the equation of the first objective function. However, by increasing the service-providing rate at the network's nodes, the second objective function, i.e. the response time, was reduced. Accordingly, it is clear that the higher was the rate at which the commodities received services at the network's nodes, the shorter would be the duration of their presence in the system and, as a result, the shorter the response time. All in all, the above-mentioned 
points imply accuracy of the model's behavior. Furthermore, it should be noted that this implication can be utilized to derive an appropriate strategy, on the basis of which, if desired, we can reduce the response time in the network without increasing the costs. According to what has been maintained thus far, one of the forthcoming strategies in this regard is to increase the service-providing rate at the network's nodes.

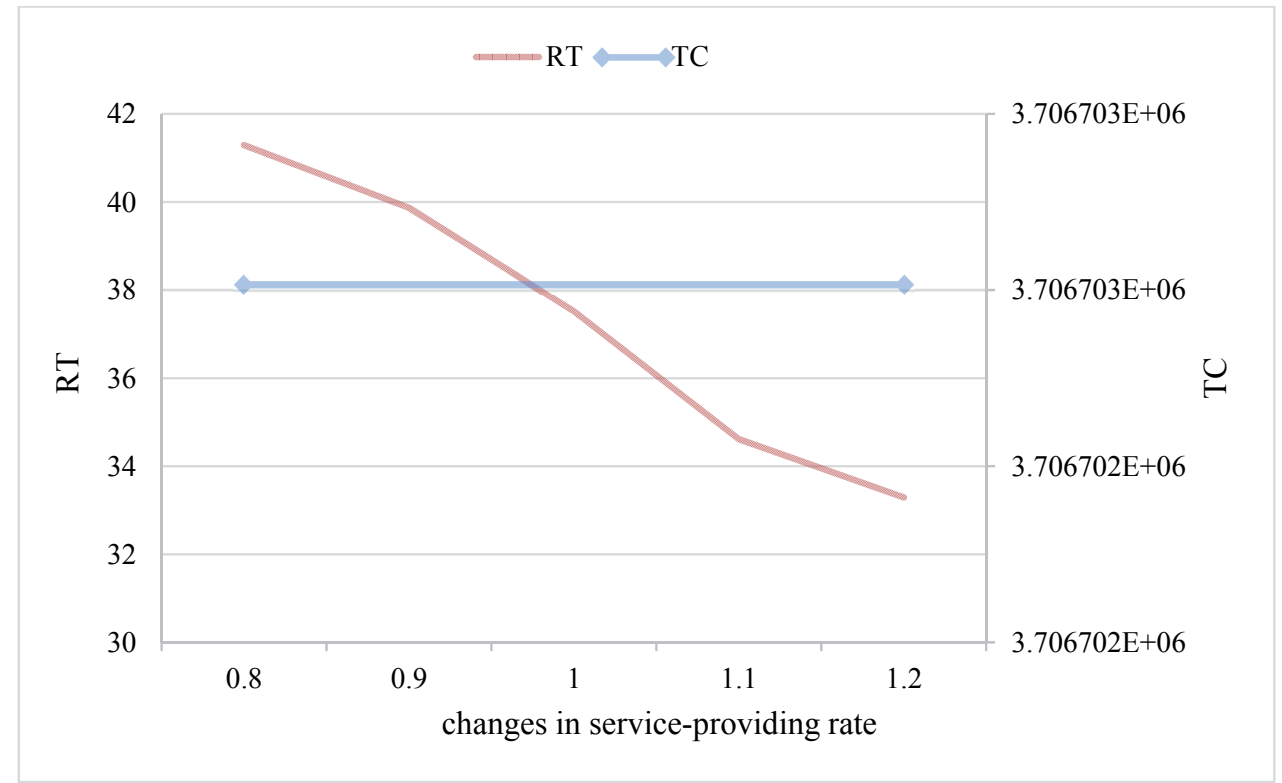

Fig. 5. Effect of changes in service-providing rate on objective functions

Fig. (6) and Fig. (7) show the effect of different values of demand occurrence rate on values of the objective functions and queue network criteria.

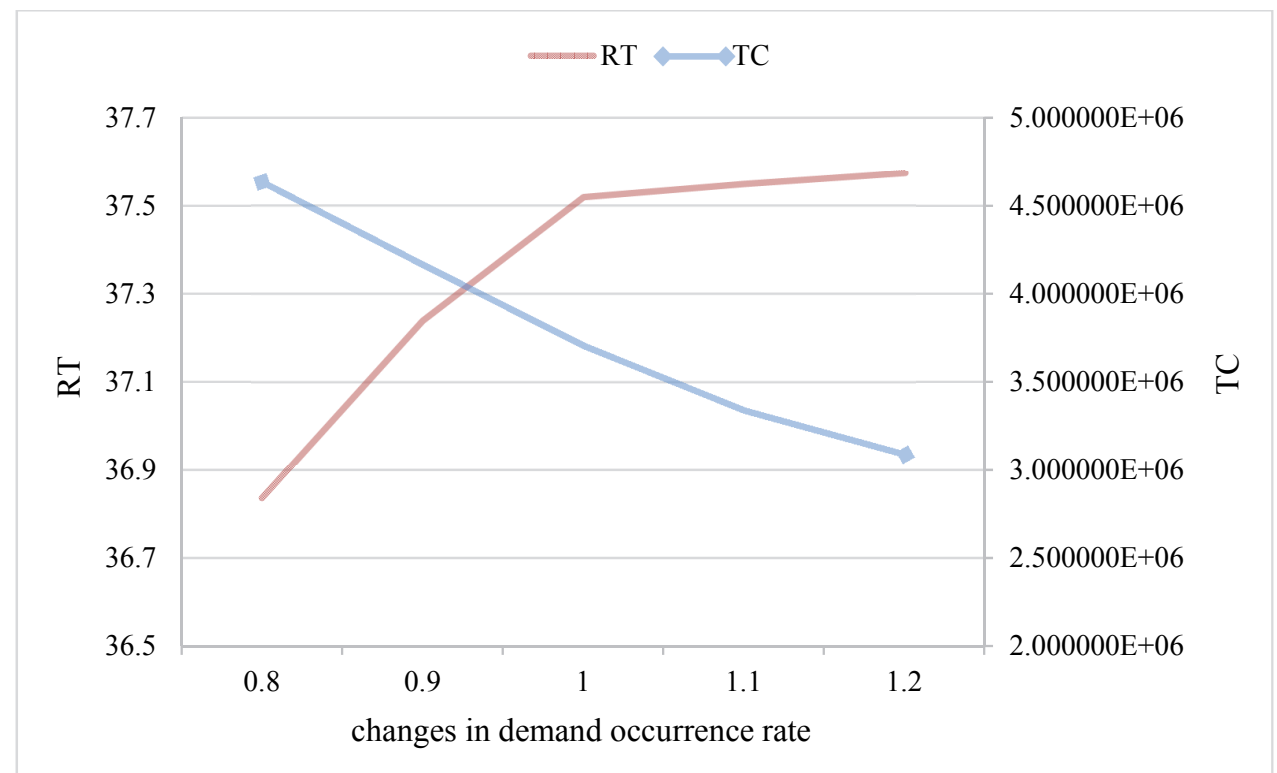

Fig. 6. Effect of changes in demand occurrence rate on objective functions

As expected, the increased demand occurrence rate led to the reduced average demand and, as a result, the increased demand entry rate. Besides, with an increase in the average demand, the total operational costs were increased as well. Such interrelationships were obviously perceivable considering the nature of the problem and equation of the first objective function. Moreover, increase in the average demand led to a reduction in the second objective function, i.e. the response time. This was natural because as much as the average demand is increased, the demand entry rate $(\lambda)$ is reduced proportionately, and the 
term $\frac{1}{\mu-\lambda}$, which represents the duration of presence in the system, is also reduced. Thus, it is expected that the duration of presence in the network would be reduced as well. Furthermore, the increased demand occurrence rate resulted in the increased time of waiting in the queue as well as increased average length of the queue, which was predictable. All the above-mentioned points exhibited validity of the model's behavior.

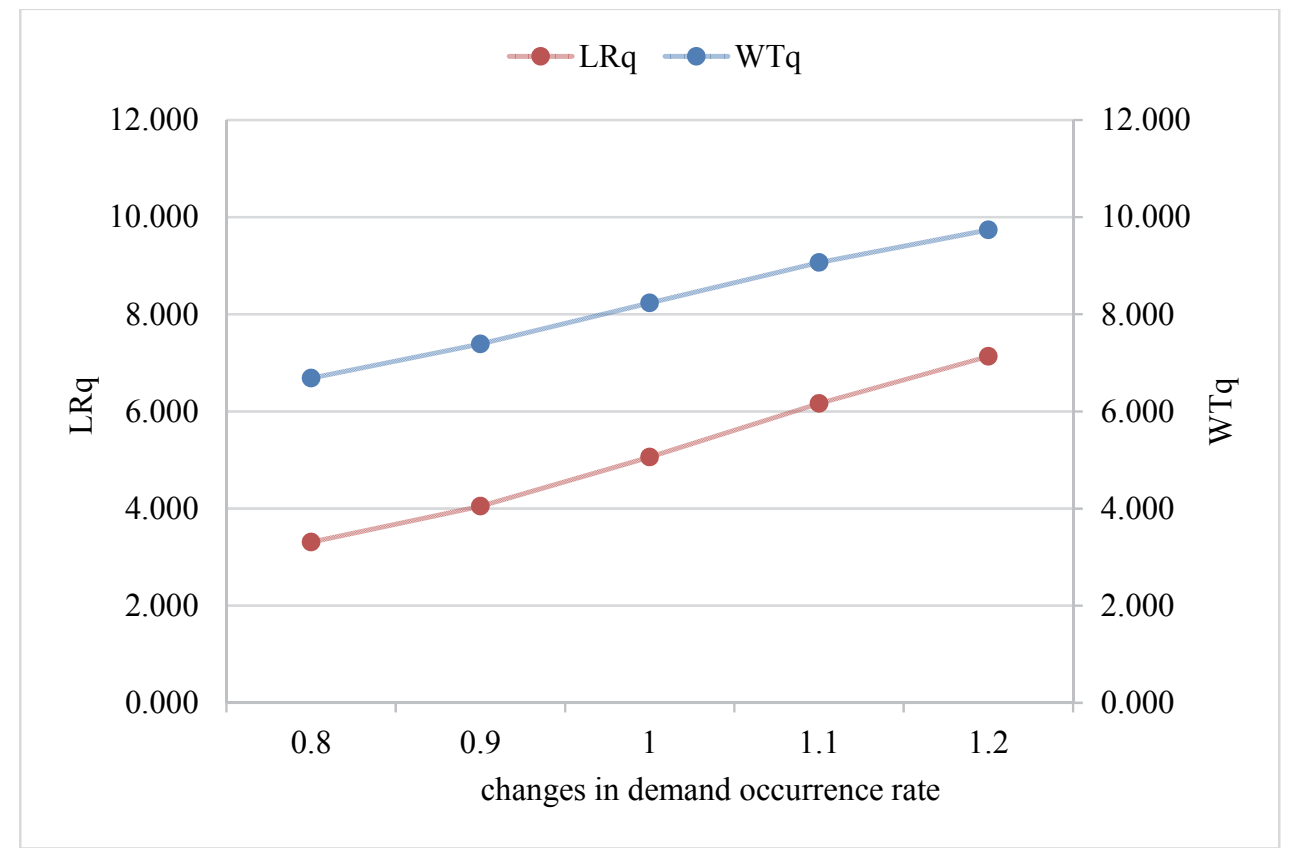

Fig. 7. Effect of changes in demand occurrence rate on queue indices

Subsequently, in order for separate investigation of the effect of changes in the carbon tax rate on the operational costs and carbon emission rate, the first objective function of the mathematical model is written as $\mathrm{TC}=\mathrm{TC} 1+\mathrm{a}^{*} \mathrm{TC} 2 . \mathrm{TC}_{1}$ indicates the total operational costs without considering the carbon tax costs and $\mathrm{TC}_{2}$ stands for the total carbon emission rate in the network. Figure (8) demonstrates the effect of different values of carbon tax rate on values of the objective functions and queuing network criteria.

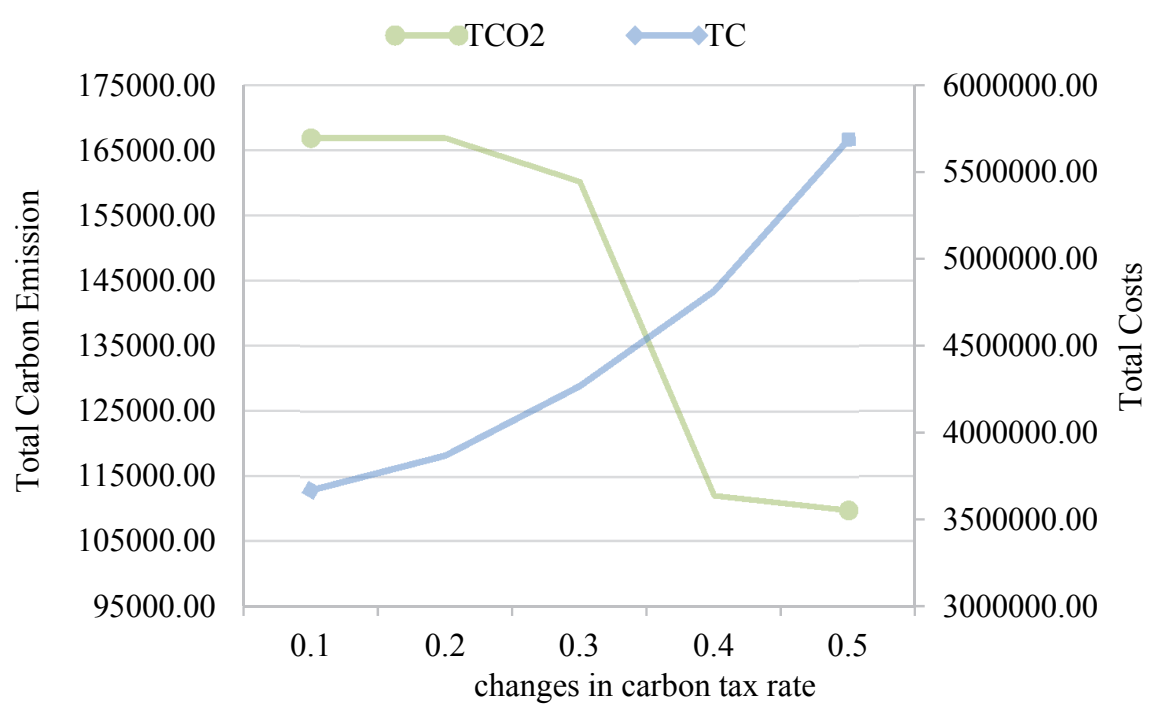

Fig. 8. Effect of changes in carbon tax rate on costs and carbon emission rate 
As shown in the above figure, with an increase in the carbon tax rate, the total operational costs were also increased due to their direct association with carbon tax rate. However, in the meantime, the carbon emission rate was reduced in the network, which indicated the desirable effect of the carbon tax policy. All in all, based on all of the above-mentioned points, validity of the model was proven.

\section{Conclusion}

For a city transport and logistics distribution system, as a considerable energy consumer and pollutiongenerator sector, saving the energy and reducing the pollutants are of great importance, especially in metropolises with massive population. Meanwhile, in some cases, it is essential to meet the demand for commodities in urban areas instantly. Such a necessity is outstandingly highlighted in cases of crisis and in relation to emergency commodities. The present paper investigated the problem of designing and planning a sustainable city logistics distribution network with the queuing theory approach as a multi-commodity bi-objective model (Arvan et al., 2015) and considering the capacity of the relevant centers and facilities. Accordingly, the first and second objectives were designed to minimize the economic and environmental costs at the network level and to minimize the response time in the network, respectively. The major innovations of the present work included the use of queuing theory approach in the city logistics distribution network design in order to improve its accuracy, flexibility, and applicability in the city logistics modelings and, furthermore, application of the carbon tax policy as well as the incentive policy of allocation of the low-carbon resources to distribution centers in order to reduce the pollutants emission rate. To investigate validity of the model's behavior, a numerical example was generated. Then, the results obtained from solving the numerical example via epsilon constraint method were presented. Furthermore, sensitivity analysis was performed on some basic parameters of the model, the results of which showed that considering the carbon tax policy would lead to the reduced carbon emission rate. The potential areas of research that can be investigated in relation to development of the mathematical model presented in this work could be proposed for further studies as following:

1. The model proposed in this work considered the network's nodes as an $M / M / 1$ queuing system. One may propose the idea that the queue system has a different model.

2. The integration of the problem presented in this work with the vehicle routing problems can be presented as an appropriate idea.

3. The problem can be viewed as a multi-period and dynamic one.

4. Since one of the major characteristics of the intra-city routes is their orthogonality, one may propose the idea that such distances can be used instead of direct distances in the future developed models.

5. Since the problems similar to the problem presented in this work are of NP-hard type, when they are applied in real cases, the exact solution methods such as epsilon constraint method might not be fast enough; thus, it would be necessary to provide meta-heuristic methods for solving the problems.

\section{References}

Anand, N., Quak, H., van Duin, R., \& Tavasszy, L. (2012). City logistics modeling efforts: Trends and gaps-A review. Procedia-Social and Behavioral Sciences, 39, 101-115.

Anand, N., Van Duin, R., Quak, H., \& Tavasszy, L. (2015). Relevance of city logistics modelling efforts: a review. Transport Reviews, 35(6), 701-719.

Arvan, M., Tavakkoli-Moghaddam, R., \& Abdollahi, M. (2015). Designing a bi-objective and multiproduct supply chain network for the supply of blood. Uncertain Supply Chain Management, 3(1), 57-68.

Babaei, A., \& Shahanaghi, K. (2017). A new model for planning the distributed facilities locations under emergency conditions and uncertainty space in relief logistics. Uncertain Supply Chain Management, 5(2), 105-125. 
Barceló, J., Grzybowska, H., \& Pardo, S. (2005). Combining vehicle routing models and microscopic traffic simulation to model and evaluating city logistics applications. In The proceedings of the 16th mini-EURO conference and 10th meeting of EWGT, Italy.

Bérubé, J. F., Gendreau, M., \& Potvin, J. Y. (2009). An exact $\epsilon$-constraint method for bi-objective combinatorial optimization problems: Application to the Traveling Salesman Problem with Profits. European Journal of Operational Research, 194(1), 39-50.

Chankong, V., \& Haimes, Y. Y. (2008). Multiobjective decision making: theory and methodology. Courier Dover Publications.

Crainic, T. G., Ricciardi, N., \& Storchi, G. (2009). Models for evaluating and planning city logistics systems. Transportation science, 43(4), 432-454.

Dablanc, L. (2007). Goods transport in large European cities: Difficult to organize, difficult to modernize. Transportation Research Part A: Policy and Practice, 41(3), 280-285.

Duren, R. M., \& Miller, C. E. (2012). Measuring the carbon emissions of megacities. Nature Climate Change, 2(8), 560.

Ehrgott, M. (2005). Multicriteria optimization (Vol. 491). Springer Science \& Business Media.

Haimes, Y. Y. (1971). On a bicriterion formulation of the problems of integrated system identification and system optimization. IEEE transactions on systems, man, and cybernetics, 1(3), 296-297.

He, X., Hu, W., Wu, J. H., \& Wang, C. (2013). Improving emergency goods transportation performance in metropolitan areas under multi-echelon queuing conditions. Procedia-Social and Behavioral Sciences, 96, 2466-2479.

Jawla, P., \& Singh, S. (2016). A reverse logistic inventory model for imperfect production process with preservation technology investment under learning and inflationary environment. Uncertain Supply Chain Management, 4(2), 107-122.

Moutaoukil, A., Neubert, G., \& Derrouiche, R. (2015). Urban Freight Distribution: The impact of delivery time on sustainability. IFAC-PapersOnLine, 48(3), 2368-2373.

Muñuzuri, J., \& Cortés, P. (2012). Recent advances and future trends in city logistics. Journal of Computational Science. 3(4), 191-192.

Teimoury, E., Saeedi, F., \& Makui, A. (2017). A mathematical model for city logistics distribution network design with the aim of minimizing response Time. International Journal of Industrial Engineering \& Production Research, 28(1), 21-31.

Taniguchi, E. (2001). City logistics: Network modelling and intelligent transport systems. Amsterdam: Pergamon.

Taniguchi, E., \& Thompson, R. G. (2015). City logistics: Mapping the future. Boston. CRC Press.

Taniguchi, E., Thompson, R. G., \& Yamada, T. (2014). Recent trends and innovations in modelling city logistics. Procedia-Social and Behavioral Sciences, 125, 4-14.

Qiu, F.Y., \& Yang, D. (2005). City Logistics in China: An Overview. In Recent Advances in City Logistics (E. Taniguchi and R. G. Thompson, eds.). Elsevier, New York, p. 417-427.

Wolpert, S., \& Reuter, C. (2012). Status quo of city logistics in scientific literature: systematic review. Transportation Research Record: Journal of the Transportation Research Board, (2269), 110-116.

Yang, J., Guo, J., \& Ma, S. (2016). Low-carbon city logistics distribution network design with resource deployment. Journal of Cleaner Production, 119, 223-228.

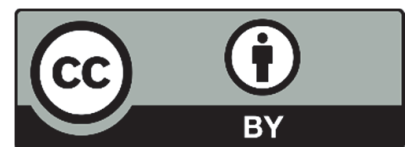

(C) 2018 by the authors; licensee Growing Science, Canada. This is an open access article distributed under the terms and conditions of the Creative Commons Attribution (CC-BY) license (http://creativecommons.org/licenses/by/4.0/). 